\title{
Development of guidance for statistical analysis plans (SAPs) for clinical trials
}

\author{
Ashma Krishan ${ }^{*}$, Deborah Stocken ${ }^{2}$, Steff Lewis ${ }^{3}$, Ed Juszczak ${ }^{4}$, Caroline Dore ${ }^{5}$, Paula Williamson ${ }^{1}$, Doug Altman ${ }^{4}$, \\ Alan Montgomery ${ }^{6}$, Mike Clarke ${ }^{7}$, Carrol Gamble ${ }^{1}$
}

From 3rd International Clinical Trials Methodology Conference

Glasgow, UK. 16-17 November 2015

\section{Background}

ICH E9 guidelines recommend that a detailed SAP is prepared before breaking the trial blind. However, the guidelines do not provide specific guidance on SAP content.

\section{Methods}

The project included: identification of existing SAP guidance; identifying and reviewing published SAPs; a survey of current practice within UKCRC registered Clinical Trial Units (rCTU) and a Delphi survey to establish consensus on SAP content. The Delphi survey included rCTU statisticians, CONSORT and SPIRIT guideline authors, experienced statisticians in the pharmaceutical industry, journal editors and regulators culminating in a face-to-face consensus meeting attended by experts from each demographic. These components informed the development of guidance for SAPs which subsequently underwent critical review by rCTU statisticians and experts from the consensus meeting, followed by piloting of the guidance document.

\section{Results}

Apart from ICH E9, no existing SAP guidance was identified. A $100 \%$ response rate from the rCTU survey was achieved which highlighted diversity in current practice confirming support for developing comprehensive guidance. The Delphi survey reached consensus on $42 \%$ (46/110) of identified components. The expert panel agreed that 63 components should be included in the guidance. The guidance was written with support of examples identified from published and unpublished SAPs.

${ }^{1}$ University of Liverpool, Liverpool, UK

Full list of author information is available at the end of the article

\section{Conclusions}

A comprehensive SAP guidance document has been developed in collaboration with the network of rCTU statisticians with the aim of facilitating its acceptance and implementation. Although the guidance document is intended primarily for CTU adoption, given the representation involved in its developments it is anticipated that it will have wider applicability.

\section{Authors' details \\ ${ }^{1}$ University of Liverpool, Liverpool, UK. ${ }^{2}$ Newcastle University, Newcastle, UK. ${ }^{3}$ University of Edinburgh, Edinburgh, UK. ${ }^{4}$ University of Oxford, Oxford, UK. ${ }^{5}$ MRC Clinical Trials Unit UCL, London, UK. ${ }^{6}$ University of Nottingham, Nottingham, UK. ${ }^{7}$ Queens University, Belfast, UK.}

Published: 16 November 2015

doi:10.1186/1745-6215-16-S2-041

Cite this article as: Krishan et al: Development of guidance for statistical analysis plans (SAPs) for clinical trials. Trials 2015 16(Suppl 2):041.

\author{
Submit your next manuscript to BioMed Central \\ and take full advantage of: \\ - Convenient online submission \\ - Thorough peer review \\ - No space constraints or color figure charges \\ - Immediate publication on acceptance \\ - Inclusion in PubMed, CAS, Scopus and Google Scholar \\ - Research which is freely available for redistribution

() Biomed Central

C 2015 Krishan et al. This is an Open Access article distributed under the terms of the Creative Commons Attribution License (http:// creativecommons.org/licenses/by/4.0), which permits unrestricted use, distribution, and reproduction in any medium, provided the original work is properly cited. The Creative Commons Public Domain Dedication waiver (http://creativecommons.org/publicdomain/ zero/1.0/) applies to the data made available in this article, unless otherwise stated. 